concludes that the removal of ultra-violet radiation by means of suitable filters, while in some instances an advantage, usually leads to only an insignificant increase in the photochemical stability of the illuminated material.

In the sarne issue of the Museums Journal, another paper, on the heating and ventilation of museums, by Dr. A. E. A. Werner, Research Laboratory at the British Museum, discusses a complex subject previously viewed in a rather empirical way. The author outlines the basic principles concerned in determining a reasonable atmospheric environment in museums and considers the practical problems involved in air-conditioning, and the various types of apparatus employed both for exhibition and storage areas. The three essentials-humidity, temperature and air movement-are considered and reasonable limits are defined. The paper is illustrated by graphs, diagrams and photographs of apparatus.

\section{Museum of Applied Arts and Sciences, Sydney}

THE annual report for 1956 of the Museum of Applied Arts and Sciences at Sydney is a purely factual statement concerning a year of progress of this well-known institution. Such is the popularity of the planetarium that serious consideration is being given to the replacement of the present projector and dome with a larger unit accommodating at least a hundred people. The chief exhibit acquired in 1956 consists of five dioramas and a flow chart presented by the Petroleum Information Bureau (Australia). The dioramas illustrate the origin of oil, exploration of potential areas, drilling processes, recovery of oil from wells, transport to refinery and uses of oil in the home. The flow chart depicts the refining of crude oil by fractional distillation. The reputation of this Museum for scientific research, especially in the field of the botany and chemistry of the essential oil-bearing flora of Australia, is being pursued, and many papers have been published.

\section{Solar Energy and the Depth of the Earth}

Since 1946 N. V. Belov and V. I. Lebedev have published a number of articles in which they have developed their hypothesis of the probable source of energy of endogenetic processes, and now they have presented their final and comprehensive outline of this hypothesis (Belov, N. V., and Lebedev, V. I. Priroda, No. 5,11 ; 1957). It is based mainly on a characteristic fact in leptology (erystal chemistry), namely, that in the minerals occurring in superficial sedimentary rocks, such as the clays, aluminium is surrounded by six oxygen atoms in octahedral co-ordination, with the Al-O distances of the order of $1.9 \mathrm{~A}$., while in the minerals of the deep-seated igneous and metamorphic rocks, such as the feldspars, aluminium is surrounded by four oxygen atoms in a tetrahedral co-ordination, with the Al-O distance of the order of $1.7 \mathrm{~A}$. The contraction of this distance during the downward movement of the Earth's crust is, according to the authors, an important source (the effect of radioactive disintegration not overlooked) of energy which produces the rise of temperature in depth, and is consequently responsible for the processes of metamorphism and magmation. Thus, aluminium and oxygen, as well as other cations, are acting as accumulators of solar energy, the charging of this 'geochemical accumulator' taking place in the zone of weathering, and its discharge in the depth of the Earth's crust. Similar conclusions have been reached by V. A. Saul (Geochim. et Cosmochim. Acta, 8, 86; 1955) entirely on the basis of the data of thermochemistry.

\section{International Union of Pure and Applied Physics}

AT the ninth General Assembly of the Inter. national Union of Pure and Applied Physics held in Rome during September 17-20.the U.S.S.R., Austria and Bulgaria were formally admitted to the Union. The number cf countries now adhering to the Union is thirty. For the period 1957-60 the Executive Committe of the Union has the following members : President, E. Amaldi (Rome) ; Former Presidents, N. F. Mott (Cambridge), M. Siegbahn (Stockholm); Vice-Presidents, J. de Boer (Amsterdam), R. B. Brode (Berkeley), M. Kotani (Tokyo), J. H. Van Vleck (Cambridge, Mass.), G. Herzberg (Ottawa), A. Joffe (Leningrad), E. Rasmussen (Copenhagen), H. Staub (Zurich), F. C. A. Trendelenburg (Erlangen), J. Weyssenhoff (Cracow); Secretary General, P. Fleury (Paris).

Eight specialized Commissions were authorized to develop international co-operation in the following fields (names of presidents and secretaries are indicated in brackets, with the addresses of the secretaries) : Symbols, units and nomenclature (H. H. Nielsen, Columbus, Ohio ; J. de Borr, Finsenstraat 28, Amsterdam, Netherlands) ; thermodynamics and statistical mechanics (J. Yvon, Paris; G. Careri, Universita degli Studi, Rome); cosmic rays (B. Rossi, Cambridge, Mass.; C. F. Powell, H. H. Wills Physical Laboratory, Royal Fort, Bristol 8) ; very low temperatures (C. J. Gorter, Leyden; D. Shoenberg, Cavendish Laboratory, Cambridge) ; publications (J. H. Awbery, London; G. A. Boutry, 292 rue Saint-Martin, Paris $3^{\circ}$ ); acoustics (W. Furrer, Berne ; C. W. Kosten, Mijnbouwplein 11, Delft, Netherlands) ; solid state physics (this commission is composed of three sub-groups): general study (J. C. Slater, Cambridge, Mass. ; C. Kittel, Department of Physics, University of California, Berkeley 4, California) ; semiconductors (A. Joffe, Leningrad; R. A. Smith, Royal Radar Establishment, Malvern); magnetism (L. N6el, Grenoble; L. F. Bates, Department of Physics, University of Nottingham); highonergy physics (C. J. Bakker, CERN, Geneva; R. E. Marshak, University of Rochester, U.S.A.).

\section{International Collegium for Neuro-Psycho-Pharma- cology}

A Meeting was held in Zurich on September 3 during the Second International Congress for Psychiatry of investigators from different countries for the purpose of founding an International Collegium for Neuro-Psycho-Pharmacology. It was decided unanimously that such a Collegium should be formed with the objects of promoting research and the exchange of ideas, as well as collaboration in the fields of experimental and clinical neuro-psychopharmacology. It is proposed to organize special symposia as well as general meetings. Prof. E. Rothlin (Switzerland) was elected president, and Profs. Trabucchi (Italy), Hoch (Ưnited States), Delay (France), Delgado (Peru), Hoff (Austria) and Dr. Shepherd (United Kingdom) as vicepresidents. It is hoped that it will be possible to hold the first international meeting of the Collegium in 1958, and an executive committee, consisting of 